\title{
Risk factors related to hypertension among patients in a cohort living with HIV/AIDS
}

\begin{abstract}
Introduction: Studies disagree as to whether there is a greater prevalence of hypertension among HIV/AIDS patients and the role of antiretroviral therapy. Objective: Evaluate the prevalence of hypertension and risk factors in a cohort of HIV-infected patients, with emphasis on antiretroviral therapy. Method: Case-control study conducted at baseline of a cohort, between June/2007 and December/2008 in Pernambuco/Brazil. Blood pressure was classified as normal, prehypertension, and hypertension. Results: Of 958 patients, 245 (25.6\%) had hypertension (cases), 325 (33.9\%) had prehypertension, and 388 (40.5\%) were normotensive (controls). Comparison between hypertensive and normotensive patients showed that traditional factors, such as age $>40(\mathrm{OR}=3.06, \mathrm{CI}=1.91$ 4.97), male gender $(\mathrm{OR}=1.85, \mathrm{CI}=1.15-3.01), \mathrm{BMI}>25(\mathrm{OR}=5.51, \mathrm{CI}=3.36-9.17)$, and triglycerides $>150 \mathrm{mg} / \mathrm{dL}(\mathrm{OR}=1.69, \mathrm{CI}=1.05-2.71)$, were independently associated with hypertension. Duration of antiretroviral therapy and CD4 $>200$ cells $/ \mathrm{mm}^{3}$ were associated with hypertension in univariate analysis, but did not remain in final model. Type of antiretroviral schema and lipodystrophy showed no association with hypertension. Conclusion: Hypertension in HIV/AIDS patients is partially linked to invariable factors, such as age and sex. Efforts should be directed toward controlling reversible factors, particularly excessive weight gain and unsuitable diet.
\end{abstract}

Keywords: HIV/AIDS, hypertension, antiretroviral therapy, cardiovascular risk.

[Braz J Infect Dis 2010;14(3):281-287] @Elsevier Editora Ltda.

\section{INTRODUCTION}

Potent antiretroviral therapy (HAART) has resulted in lasting suppression of HIV replication, reduction of opportunistic infections and malignancies associated with AIDS, and has had a substantial impact on the survival rate and quality of life of infected individuals. ${ }^{1}$ However, the potential to keep these patients under treatment for decades may be limited by a variety of metabolic and cardiovascular abnormalities observed in patients on HAART, including dyslipidemia, fat redistribution, insulin resistance, ${ }^{2}$ hypertension, ${ }^{3}$ and coronary ischemia. ${ }^{4}$

Two large prospective studies ${ }^{4,5}$ showed that the HIV infected population is at increased risk of cardiovascular disease in the long term. However, individual cardiovascular risk is determined by a complex overlapping of several risk factors that include age, family history, smoking, hypertension, diabetes, and high blood lipids. ${ }^{6}$ In the period prior to HAART, high blood pressure in infected patients was often associated with complications related to HIV, such as renal failure and vasculopathy. ${ }^{7}$ In postHAART period, some studies have raised the possibility that HAART may also induce hypertension ${ }^{8-15}$ through the acceleration of atherogenesis and subsequent hardening of the vessel wall. ${ }^{16}$

Studies on blood pressure in HIV infected patients show conflicting results regarding the increased prevalence of disease among patients on HAART and the role of different treatment regimens in its genesis. ${ }^{3,13,17,18}$ Given the importance of the subject and the urgency in adopting preventive measures for cardiovascular damage among patients with HIV/AIDS on antiretroviral treatment, this study was conducted to assess the prevalence of hypertension and possible risk factors in a cohort of 1,000 HIV patients, paying particular attention to the role of antiretrovirals in the development of the disease.
Authors

Evanizio Roque de Arruda Junior, $\mathrm{MD}, \mathrm{PhD}^{1}$ Heloisa Ramos Lacerda, $\mathrm{MD}, \mathrm{PhD}^{2}$

Libia Cristina Rocha Vilela Moura, MD, $\mathrm{MSc}^{2}$ Maria de Fatima Pessoa Militão de Albuquerque, $\mathrm{MD}, \mathrm{PhD}^{3}$

Democrito de Barros Miranda Filho, $\mathrm{MD}, \mathrm{PhD}^{2}$ George Tadeu Nunes Diniz, $\mathrm{MSc}^{3}$

Valeria Maria Gonçalves de Albuquerque, MD, $\mathrm{MSc}^{2}$

Josefina Cláudia Zirpoli Amaral, MD, MSc ${ }^{2}$

Ricardo Alencar de Arraes Ximenes, $\mathrm{MD}, \mathrm{PhD}^{2}$

Verônica Soares

Monteiro, MD, MSc ${ }^{2}$

${ }^{1}$ Universidade Federal da Paraíba, Brazil.

${ }^{2}$ Universidade Federal de Pernambuco, Brazil. ${ }^{3}$ Centro de Pesquisa Aggeu Magalhães, Ministry of Health, Brazil.

Submitted on: 03/03/2010 Approved on: 04/30/2010

Correspondence to: Evanizio Roque de Arruda Junior

Universidade Federal da Paraíba

Av. João Mauricio, 1229, Manaira João Pessoa - PB - Brazil CEP: 58038-000 Phone: +55-83-32478898 Fax: +55-81-21268527 E-mail:

evanizio@cardiol.br

This project is funded by the National STD/AIDS Program of the Brazilian Ministry of Health. 


\section{METHODS}

A case-control study was conducted at baseline assessment of a cohort of outpatients with HIV/AIDS treated at the Infectious Diseases Unit, Oswaldo Cruz Medical College, University of Pernambuco and Correia Picanço Hospital of the Pernambuco State Department of Health, Brazil, from June 2007 to December 2008, and evaluated consecutively. After receiving the information, patients signed the informed consent form, answered a questionnaire and were submitted to measurement of anthropometric data, blood pressure and collection of blood samples to assess fasting blood glucose and lipids. Data on HIV infection and antiretroviral therapy were obtained from medical records. The study was approved by the Ethics Committee (protocol number 052/05). All participants were aged 18 years or over. Pregnant women and patients with signs of active AIDS or hospitalization in the previous three months were excluded.

Diagnosis of hypertension was confirmed on a second visit, not more than two months later, when two BP measurements were taken in an upper limb, and mean systolic and diastolic pressures were calculated. Patients were classified according to the criteria of the Joint $\mathrm{Na}$ tional Committee on Prevention, Detection, Evaluation, and Treatment of High Blood Pressure (JNC 7), ${ }^{19}$ which considers the following classifications of blood pressure: normal (systolic $\mathrm{BP}<120 \mathrm{mmHg}$ and diastolic $\mathrm{BP}<80$ $\mathrm{mmHg}$ ); prehypertension (systolic BP between 120-139 $\mathrm{mmHg}$ or diastolic BP between $80-89 \mathrm{mmHg}$ ); and hypertension (systolic BP > $140 \mathrm{mmHg}$ and diastolic $\mathrm{BP}>$ $90 \mathrm{mmHg}$ ).

Cases were defined as patients with systolic BP $>140$ $\mathrm{mmHg}$ and diastolic BP $>90 \mathrm{mmHg}$, measured on at least two occasions, or a previous diagnosis of hypertension and blood pressure levels controlled with an antihypertensive drug. Patients with normal blood pressure (systolic $\mathrm{BP}<120 \mathrm{mmHg}$ and diastolic $\mathrm{BP}<80 \mathrm{mmHg}$ ) were considered controls.

\section{DATA ANALYSIS}

All univariate and multivariate analyses were carried out using the R statistical program (R Project for Statistical Computing www.r-project.org).

To test the assumption of normality for continuous variables involved in the study, the Shapiro Wilk test was used. In the comparative analysis of quantitative variables we used Student t-test. Chi-square and, when necessary, Fisher's test was used to test the association between dependent variable and potential risk factors. All conclusions were drawn at a $5 \%$ level of significance.

All the variables that, in the univariate analysis, showed a p-value $<0.25$ for association with the depend- ent variable were introduced in a multivariate model (multiple logistic regression), by block, and those that remained in the model had a $\mathrm{p}$-value of $<0.05$. Then there was a final multivariate analysis that included the variables selected in each block, using as a cutoff point a p-value $<0.05$.

\section{RESULTS}

Of the 1,000 HIV-positive patients eligible for the study, 958 agreed to participate and attended two or more visits. Hypertension was detected in 245 patients (25.6\%), $36(14.8 \%)$ of which were controlled with an antihypertensive drug. A total of 325 (33.9\%) had pre-hypertension and $388(40.5 \%)$ were normotensive (controls). In the univariate analysis, the mean age of hypertensive patients (Figure 1) was significantly higher than that of prehypertensive and hypertensive ones $(43.4+9.2$ years X $40.4+9.8$ years X $36.9+8.9$ years $(\mathrm{p}<0.0001)$. The average duration of antiretroviral drugs use (Figure 2) was higher in hypertensive patients than in controls $(1,742.6+1,211.5 \times 1,389.2+1,182.6$ days $)(p=0.0088)$, and waist circumference was also higher in hypertensive patients than in prehypertensive and normotensive ones $(80.7+8.7 \mathrm{~cm} \mathrm{X} 86.6+10.1 \mathrm{~cm} \mathrm{X} 90.2+10.5 \mathrm{~cm})$ $(\mathrm{p}<0.0001)$.

In the univariate analysis of biological factors, age, male gender, and a family history of hypertension were associated with hypertension (Table 1); and among living habits, the consumption of vegetables and level of physical activity were associated with the presence of disease (Table 2). Of the metabolic characteristics, BMI $>25$, high waist circumference $\left(\right.$ NCEP criteria) ${ }^{20}$, level of cholesterol $>200 \mathrm{mg} / \mathrm{dL}$, blood glucose levels $>100 \mathrm{mg} / \mathrm{dL}$, and triglyceride values of $>150 \mathrm{mg} / \mathrm{dL}$ were associated with hypertension. In contrast, lipodystrophy was not associated with the disease (Table 3).

On assessing the factors associated with infection and antiretroviral treatment, we observed that CD4lymphocyte count $<200$ cells $/ \mathrm{mm}^{3}$, time elapsed since the diagnosis of HIV infection $>5$ years, time elapsed since the diagnosis of AIDS, and duration of antiretroviral treatment $>1$ year were all associated with the presence of hypertension. In this same analysis, the use of antiretroviral regimens containing protease inhibitors was not associated with hypertension (Table 4).

Figure 3 presents the results of multivariate logistic regression and show that age $>40$ years $(\mathrm{OR}=3.06, \mathrm{CI}$ =1.91-4.97), male gender $(\mathrm{OR}=1.85, \mathrm{CI}=1.15-3.01)$, body mass index $>25(\mathrm{OR}=5.51, \mathrm{CI}=3.36-9.17)$, and triglycerides $>150 \mathrm{mg} / \mathrm{dL}(\mathrm{OR}=1.69, \mathrm{CI}=1.05-2.71)$ were independently and significantly associated with hypertension. 
Figure 1: Mean and standard deviation of age of patients with HIV/AIDS with hypertension (cases), prehypertension and normotensive (controls).

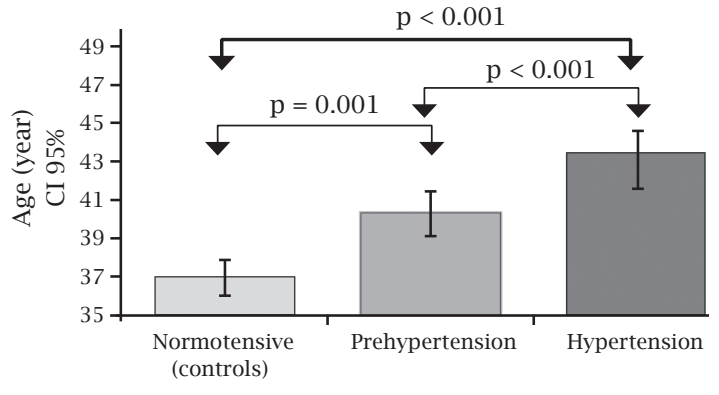

Figure 2: Mean and standard deviation of duration of therapy (in days) in patients with HIV/AIDS with hypertension (cases), prehypertension and normotensive (controls).

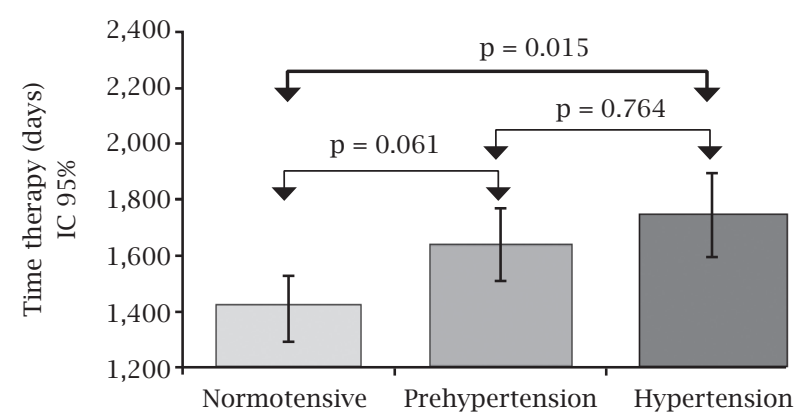

Figure 3: Model of the final multivariate analysis of association between hypertension and biological characteristics, living habits, metabolic and anthropometric factors related to HIV infection and antiretroviral therapy.

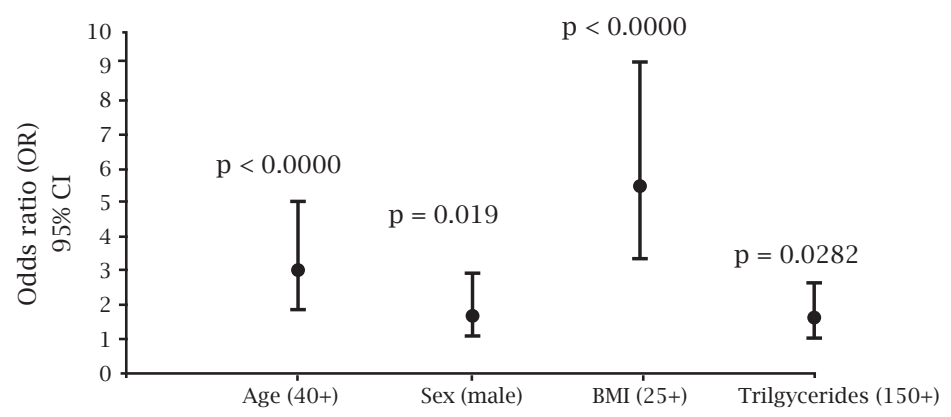

Table 1. Comparison of biological characteristics of 245 hypertensive patients (cases) and 388 normotensives (controls) in a cohort of individuals living with HIV/AIDS in Pernambuco, Brazil

\begin{tabular}{|c|c|c|c|c|c|c|c|c|}
\hline \multirow[t]{2}{*}{ Biological factors } & \multicolumn{2}{|c|}{ Hypertensive } & \multicolumn{2}{|c|}{ Normotensive } & \multirow{2}{*}{ OR } & \multicolumn{2}{|c|}{$95 \%$ CI } & \multirow{2}{*}{ p-value } \\
\hline & $\mathbf{n}$ & $\%$ & $\mathbf{n}$ & $\%$ & & lower & upper & \\
\hline \multicolumn{9}{|l|}{ Age } \\
\hline$<40$ & $89 / 245$ & 36.33 & $241 / 388$ & 62.11 & 1.00 & - & - & - \\
\hline $40+$ & $156 / 245$ & 63.67 & $147 / 388$ & 37.89 & 2.87 & 2.06 & 4.01 & $<0.0001$ \\
\hline \multicolumn{9}{|l|}{ Sex } \\
\hline Female & $89 / 245$ & 36.33 & $175 / 388$ & 45.10 & 1.00 & - & - & - \\
\hline Male & $156 / 245$ & 63.67 & $213 / 388$ & 54.90 & 1.44 & 1.04 & 2.00 & 0.0292 \\
\hline \multicolumn{9}{|l|}{ Ethnicity } \\
\hline White & $63 / 245$ & 25.71 & $106 / 388$ & 27.32 & 1.00 & - & - & - \\
\hline Black & $28 / 245$ & 11.43 & $43 / 388$ & 11.08 & 1.1 & 0.62 & 1.94 & 0.7531 \\
\hline Yellow & $4 / 245$ & 1.63 & $5 / 388$ & 1.29 & 1.35 & 0.31 & 5.49 & 0.7305 \\
\hline Brown & $145 / 245$ & 59.18 & $227 / 388$ & 58.51 & 1.07 & 0.74 & 1.57 & 0.7063 \\
\hline Indigenous & $5 / 245$ & 2.04 & $7 / 388$ & 1.8 & 1.21 & 0.34 & 4.05 & 0.7656 \\
\hline \multicolumn{9}{|c|}{ Family history of hypertension } \\
\hline No & $174 / 245$ & 71.02 & $231 / 388$ & 60.31 & 1.00 & - & - & - \\
\hline Yes & $52 / 245$ & 21.22 & $116 / 388$ & 30.29 & 1.68 & 1.15 & 2.47 & 0.0077 \\
\hline Not known & $19 / 245$ & 7.76 & $36 / 388$ & 9.4 & 1.18 & 0.61 & 2.23 & 0.6197 \\
\hline
\end{tabular}

$\chi 2$, chi-square; OR, odds ratio. 
Table 2. Comparison of lifestyle of 245 hypertensive and 388 normotensive patients in a cohort of individuals with HIV/AIDS in Pernambuco, Brazil

\begin{tabular}{|c|c|c|c|c|c|c|c|c|}
\hline \multirow[t]{2}{*}{ Lifestyle } & \multicolumn{2}{|c|}{ Hypertensive } & \multicolumn{2}{|c|}{ Normotensive } & \multirow{2}{*}{ OR } & \multicolumn{2}{|c|}{$95 \% \mathrm{CI}$} & \multirow{2}{*}{ p-value } \\
\hline & $\mathbf{n}$ & $\%$ & $\mathbf{n}$ & $\%$ & & lower & upper & \\
\hline \multicolumn{9}{|l|}{ Smoking history } \\
\hline Never smoked & $109 / 242$ & 45.04 & $167 / 384$ & 43.49 & 1.00 & - & - & - \\
\hline Former smoker & $77 / 242$ & 31.82 & $111 / 384$ & 28.91 & 1.06 & 0.73 & 1.55 & 0.7520 \\
\hline Current smoker & $56 / 242$ & 23.14 & $106 / 384$ & 27.6 & 0.81 & 0.54 & 1.21 & 0.3048 \\
\hline \multicolumn{9}{|l|}{ Cocaine } \\
\hline Never used & $227 / 244$ & 93.03 & $348 / 388$ & 89.69 & 1.00 & - & - & - \\
\hline Already used & $17 / 244$ & 6.97 & $40 / 388$ & 10.31 & 0.65 & 0.86 & 2.83 & 0.1533 \\
\hline \multicolumn{9}{|l|}{ Consumption of alcohol } \\
\hline Teetotaler / Light drinker & $201 / 228$ & 88.16 & $304 / 348$ & 87.36 & 1.00 & - & - & - \\
\hline Heavy / Dependent drinker & $27 / 228$ & 11.84 & $44 / 348$ & 12.64 & 0.93 & 0.55 & 1.54 & 0.7747 \\
\hline \multicolumn{9}{|l|}{ Consumption of vegetables } \\
\hline Yes & $171 / 240$ & 71.25 & $242 / 383$ & 63.19 & 1.00 & - & - & - \\
\hline No & $69 / 240$ & 28.75 & $141 / 383$ & 36.81 & 0.69 & 0.49 & 0.98 & 0.0387 \\
\hline \multicolumn{9}{|l|}{ Consumption of fruits } \\
\hline Yes & 139 & 57.68 & 193 & 50.79 & 1.00 & - & - & - \\
\hline No & $102 / 241$ & 42.32 & $187 / 380$ & 49.21 & 0.77 & 0.56 & 1.06 & 0.1150 \\
\hline \multicolumn{9}{|l|}{ Physical activity } \\
\hline High & $60 / 245$ & 24.49 & $105 / 388$ & 27.06 & 1.00 & - & - & - \\
\hline Moderate & $56 / 245$ & 18.37 & $58 / 388$ & 7.99 & 1.89 & 1.14 & 3.14 & 0.0133 \\
\hline Low & $141 / 245$ & 53.88 & $236 / 388$ & 56.96 & 1.17 & 0.78 & 1.76 & 0.4478 \\
\hline
\end{tabular}

ఒ2, chi-square; OR, Odds Ratio.

Table 3. Comparison of anthropometric and metabolic characteristics of 245 hypertensive and 388 normotensive patients in a cohort of individuals with HIV/AIDS in Pernambuco, Brazil

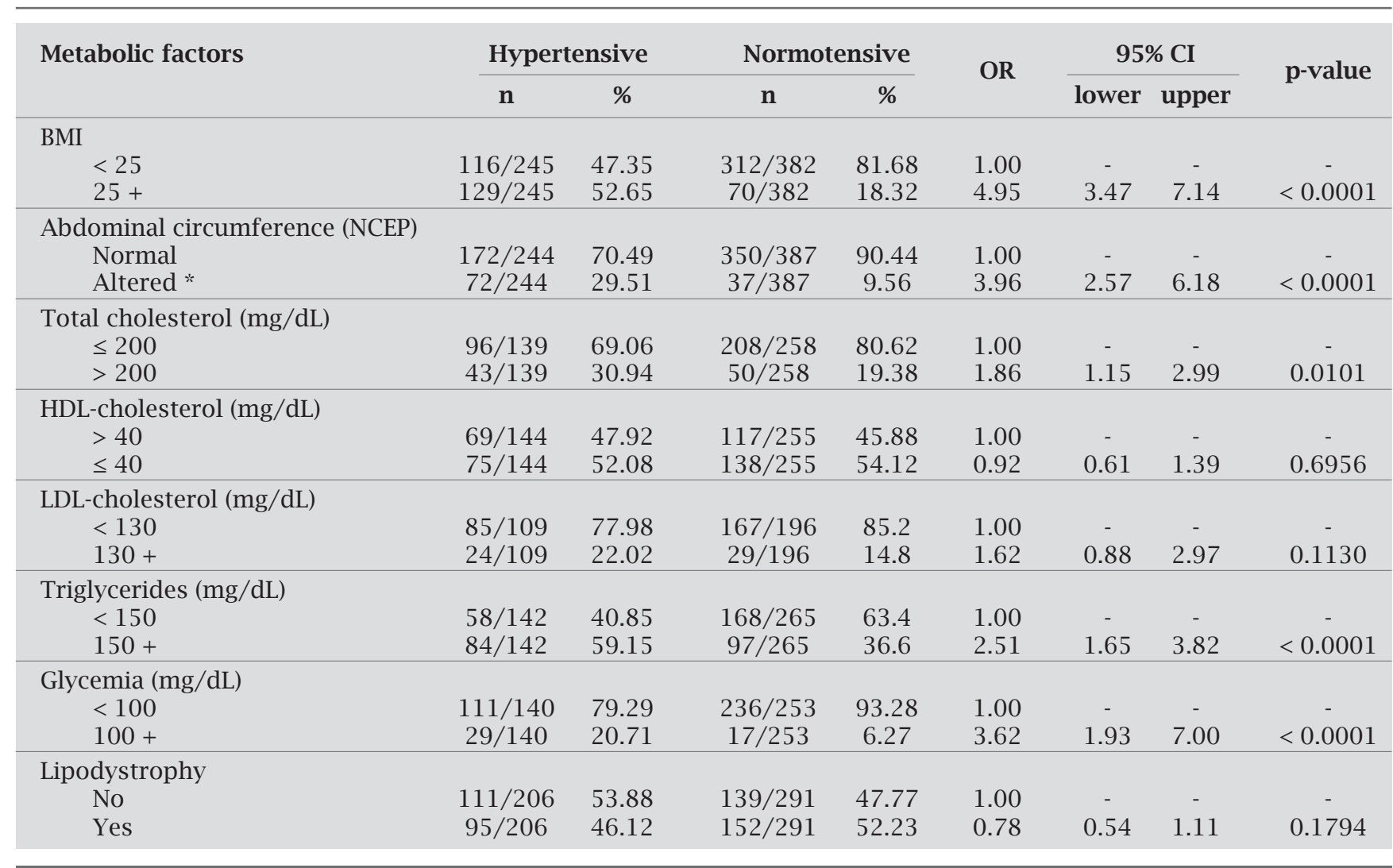

$\chi 2$, chi-square; OR, odds ratio.

* Altered $=$ Women $>88 \mathrm{~cm}$; Men $>102 \mathrm{~cm}$ 
Table 4. Comparison of factors related to HIV infection and antiretroviral therapy in 245 hypertensive and 388 normotensive patients in a cohort of individuals with HIV/AIDS in Pernambuco, Brazil

\begin{tabular}{|c|c|c|c|c|c|c|c|c|}
\hline \multirow{2}{*}{$\begin{array}{l}\text { Factors related } \\
\text { to HIV infection }\end{array}$} & \multicolumn{2}{|c|}{ Hypertensive } & \multicolumn{2}{|c|}{ Normotensive } & \multirow{2}{*}{ OR } & \multicolumn{2}{|c|}{$95 \% \mathrm{CI}$} & \multirow{2}{*}{ p-value } \\
\hline & $\mathbf{n}$ & $\%$ & $\mathbf{n}$ & $\%$ & & lower & upper & \\
\hline \multicolumn{9}{|l|}{ Use of HAART } \\
\hline No & $38 / 217$ & 17.51 & $71 / 343$ & 20.7 & 1.00 & - & - & - \\
\hline Yes & $179 / 217$ & 82.49 & $272 / 343$ & 79.3 & 1.23 & 0.80 & 1.92 & 0.3537 \\
\hline \multicolumn{9}{|l|}{ Current HAART status } \\
\hline Without HAART & $30 / 214$ & 13.62 & $61 / 327$ & 18.65 & 1.00 & - & - & - \\
\hline With PI & $89 / 214$ & 41.78 & $141 / 327$ & 43.12 & 1.28 & 0.77 & 2.16 & 0.3388 \\
\hline Without PI & $95 / 214$ & 44.60 & $125 / 327$ & 38.23 & 1.55 & 0.93 & 2.60 & 0.0957 \\
\hline \multicolumn{9}{|c|}{ Duration of HAART exposure } \\
\hline Up to 1 year & 21/169 & 12.43 & $68 / 254$ & 26.77 & 1.00 & - & - & \\
\hline 1 to 5 years & $80 / 169$ & 47.34 & $102 / 254$ & 40.16 & 2.53 & 1.46 & 4.51 & 0.0014 \\
\hline $5+$ years & $68 / 169$ & 40.23 & $84 / 254$ & 33.07 & 2.62 & 1.49 & 4.72 & 0.0013 \\
\hline \multicolumn{9}{|c|}{ Time of diagnosis of HIV } \\
\hline Up to 1 year & $19 / 153$ & 12.42 & $49 / 253$ & 19.37 & 1.00 & - & - & - \\
\hline 1 to 5 years & $61 / 153$ & 39.87 & $113 / 253$ & 44.66 & 1.39 & 0.76 & 2.62 & 0.2912 \\
\hline $5+$ years & $73 / 153$ & 47.71 & $91 / 253$ & 35.97 & 2.07 & 1.14 & 3.89 & 0.0200 \\
\hline \multicolumn{9}{|l|}{ CD4 Nadir } \\
\hline $200+$ & $119 / 188$ & 66.30 & $168 / 290$ & 57.93 & 1.00 & - & - & - \\
\hline $100-200$ & $33 / 188$ & 17.55 & $56 / 290$ & 19.31 & 0.83 & 0.59 & 1.15 & 0.2750 \\
\hline$<100$ & $36 / 188$ & 19.15 & $66 / 290$ & 22.76 & 1.04 & 0.70 & 1.56 & 0.8310 \\
\hline \multicolumn{9}{|c|}{ Current CD4 lymphocyte count } \\
\hline $500+$ & $49 / 126$ & 38.89 & $63 / 200$ & 31.50 & 1.00 & - & - & - \\
\hline $200-500$ & $61 / 126$ & 48.41 & $98 / 200$ & 49.00 & 0.80 & 0.49 & 1.31 & 0.3743 \\
\hline$<200$ & $16 / 126$ & 12.70 & $39 / 200$ & 19.50 & 0.53 & 0.26 & 1.04 & 0.0698 \\
\hline \multicolumn{9}{|l|}{ Current viral load } \\
\hline$<10,000$ & $54 / 67$ & 80.60 & $92 / 119$ & 77.31 & 1.00 & - & - & - \\
\hline $10,000-100,000$ & $8 / 67$ & 11.94 & 22/119 & 18.49 & 0.62 & 0.24 & 1.44 & 0.2841 \\
\hline $100,000+$ & $5 / 67$ & 7.46 & $5 / 119$ & 4.20 & 1.42 & 0.39 & 4.93 & 0.5776 \\
\hline
\end{tabular}

\section{DISCUSSION}

Although blood pressure levels are usually considered in studies of cardiovascular disease risk in populations of HIV-infected patients, the prevalence of hypertension, the focus of this study, has received little attention, and data are controversial and vary widely. ${ }^{3,13,14,21}$ Possible explanations for these discrepant results include differences in study design, methodological aspects, the cut values for hypertension and differences in the populations studied. Using the Joint National Committee on Prevention, Detection, Evaluation, and Treatment of High Blood Pressure (JNC 7) criteria, ${ }^{19} 25.6 \%$ of 958 patients with HIV/AIDS are hypertensive, a proportion similar to that found in the region, and in Brazil as a whole, in uninfected individuals. ${ }^{22,23}$

The comparison between HIV/AIDS non-hypertensive and hypertensive patients showed that traditional risk factors were associated with the presence of hypertension, such as older age, male gender, overweight/obesity, family history of hypertension, and increased levels of triglycerides. Lipodystrophy was not associated with the presence of hypertension. The duration of HAART exposure was associated with hypertension and the levels of CD4 lymphocytes below 200 cells $/ \mathrm{mm}^{3}$ showed a tendency to be protective against hypertension in univariate analysis; nevertheless, none of them remained in the final model. The type of antiretroviral schema was not associated with the onset of hypertension.

The findings of this study reinforce the hypothesis that HIV/AIDS and/or antiretroviral therapy, despite significantly increase the risk of atherosclerosis and cardiovascular disease, ${ }^{4,17}$ do not appear to have a significant impact on the prevalence and genesis of hypertension compared with the factors traditionally associated with the disease, which is in agreement with the findings of Baekken et al., ${ }^{3}$ Bergensen et al. ${ }^{13}$ and Khalsa et al. ${ }^{21}$ 
There are, however, a number of aspects that deserve special mention: while the presence of lipodystrophy, hypercholesterolemia, and low levels of HDL fraction of cholesterol were not associated with hypertension, the increase in triglycerides was associated with the disease. Considering that the serum triglycerides are the lipids that most frequently undergo change with the use of anti-retrovirals, ${ }^{24}$ the question arises as to whether this increase does not reflect the association of hypertension with the use of HAART for long periods or the use of some specifically antiretroviral schema, especially a schema containing Protease Inhibitors (PI), as suggested by Baekken et al., ${ }^{3}$ Crane et al..$^{18}$ The rise in triglyceride levels related to antiretroviral treatment is higher for the first generation of non-nucleoside reverse transcriptase inhibitors (efavirenz and nevirapine) than for the protease inhibitors (PI), although the rise in LDL cholesterol is similar in both groups. ${ }^{24}$ Moreover, the drugs of the group of nucleoside reverse transcriptase inhibitors, such as stavudine and zidovudine, may also play a role in these changes. ${ }^{24}$ As for the PI, the highest rises in triglycerides are associated with booster regimens containing ritonavir. ${ }^{24}$ Bearing in mind that preferred antiretroviral regimens suggested by the National STD/AIDS Program in Brazil is composed of zidovudine and lamivudine associated with efavirenz or one boosted PI (lopinavir or atazanavir both boosted with ritonavir), ${ }^{25}$ the increase in triglycerides could signal the use of HAART in its different treatment regimens, without any preferential schema. On the other hand, as mentioned above, the duration of antiretroviral therapy was associated with hypertension in the univariate analysis, but this factor was no longer present in the multivariate analysis. Furthermore, the combination of an increase in triglycerides and hypertension could merely reflect a dietary disorder, or a diet rich in carbohydrates, so common among the obese.

As for obesity, this was a risk factor strongly associated with hypertension in this study, as in all studies that deal with hypertension in the general population. ${ }^{19,22}$ Obesity of individuals with HIV/AIDS may be associated with excessive weight gain during treatment with HAART and should be avoided. However, while uninfected individuals often have the desire and strive to lose weight, among the infected patients, particularly those who already had symptoms of AIDS, the loss of weight enhances the fantasy of appearing ill and this is a "taboo" among the infected. Thus, it is not only lipodystrophy that merits attention. A recent Brazilian study showed that the majority of adults living with HIV/ AIDS have a diet that needs improvement, and obesity was associated with a poorer quality of diet. ${ }^{26}$ Nutritional interventions aimed at maintaining a healthy weight should be emphasized in the care of HIV patients $s^{25}$ and may offer protection against the onset of hypertension in this group.

Moreover, in subjects with CD4 $<200$, the risk of hypertension was lower. Certainly, loss of weight, and lower levels of triglycerides, most frequently found in patients with CD4 lymphocyte counts of less than 200 cells $/ \mathrm{mm}^{3},{ }^{24,27}$ could be reflected in the lower prevalence of hypertension in this group.

This study has the limitations inherent in a case control study, i.e., it does not determine the origin but the combination of factors, and data reflect a specific population (young and predominantly male). However, it has the advantage of being a study in which patients were prospectively selected based on the criteria of JNC 7 and of having excluded prehypertensive patients from the analysis, thereby highlighting the differences between the groups.

Finally, hypertension in patients with HIV/AIDS is associated with factors such as age $>40$ years, BMI $>25$, high triglyceride level, and male gender. Therefore, the control of the reversible factors associated with hypertension, particularly the reinforcement of dietary advice guidance and prevention of excessive weight gain, may represent an important advance in the prevention of cardiovascular morbidity among people living with HIV/AIDS.

\section{REFERENCES}

1. Antiretroviral Therapy Cohort Collaboration. Life expectancy of individuals on combination antiretroviral therapy in high-income countries: a collaborative analysis of 14 cohort studies. Lancet 2008; 372:293-9.

2. Hadigan C, Meigs JB, Corcoran C et al. Metabolic abnormalities and cardiovascular disease risk factors in adults with human immunodeficiency virus infection and lipodystrophy. Clin Infect Dis 2001; 32:130-9.

3. Baekken M, Os I, Sandvik L et al. Hypertension in an urban HIV-positive population compared with the general population: influence of combination antiretroviral therapy. J Hypertens 2008; 26:2126-33.

4. DAD Study Group, Friis-Møller N, Reiss P, Sabin CA et al. Class of antiretroviral drugs and the risk of myocardial infarction. N Engl J Med 2007; 356:1723-35.

5. Mary-Krause M, Cotte L, Simon A et al. Increased risk of myocardial infarction with duration of protease inhibitor therapy in HIV-infected men. AIDS 2003; 17:247986.

6. Yusuf S, Hawken S, Ounpuu S et al. Effect of potentially modifiable risk factors associated with myocardial infarction in 52 countries (the INTERHEART study): a case control study. Lancet 2004; 364:937-52.

7. Winston J, Klotman PE. HIV-associated nephropathy. Mt Sinai J Med 1998; 65:27-32.

8. Aoun S, Ramos E. Hypertension in the HIV-infected patient. Curr Hypertens Rep 2000; 2:478-81.

9. Sattler FR, Qian D, Louie S et al. Elevated blood pressure in subjects with lipodystrophy. AIDS 2001; 15:2001-10.

10. Chow DC, Souza SA, Chen R et al. Elevated blood pressure in HIV-infected individuals receiving highly active antiretroviral therapy. HIV Clin Trials 2003; 4:411-6.

11. Gazzaruso C, Bruno R, Garzaniti A et al. Hypertension among HIV patients: prevalence and relationships to insulin resistance and metabolic syndrome. J Hypertension 2003; 21:1377-82. 
12. Galindo Puerto MJ. AHT and HIV - a new problem? Nutr Metab Disord HIV Infect 2002; 1:33-7.

13. Bergersen BM, Sandvik L, Dunlop O et al. Prevalence of hypertension in HIV-positive patients on highly active retroviral therapy (HAART) compared with HAART-naive and HIVnegative controls: results from a Norwegian study of 721 patients. Eur J Clin Microbiol Infect Dis 2003; 22:731-6.

14. Palacios R, Santos J, García A et al. Impact of highly active antiretroviral therapy on blood pressure in HIV-infected patients. A prospective study in a cohort of naive patients. HIV Med 2006; 7:10-5.

15. Coloma Conde AG, Alvarez Albarrán M, Roca-Cusachs Coll A et al. Prevalence of arterial hypertension and lipid profile in HIV patients. Med Clin (Barc) 2008;131:681-4.

16. Dubé MP, Lipshultz SE, Fichenbaum CJ et al. Effects of HIV infection and antiretroviral therapy on the heart and vasculature. Circulation 2008; 118:e36-e40.

17. Thiébaut R, El-Sadr WM, Friis-Møller N et al. and Data Collection of Adverse events of anti-HIV Drugs Study Group. Predictors of hypertension and changes of blood pressure in HIV-infected patients. Antivir Ther 2005; 10:811-23.

18. Crane HM, Van Rompaey SE, Kitahata MM. Antiretroviral medications associated with elevated blood pressure among patients receiving highly active antiretroviral therapy. AIDS 2006; 20:1019-26.

19. Chobanian AV, Bakris GL, Black HR et al. and Joint National Committee on Prevention, Detection, Evaluation, and Treatment of High Blood Pressure. National Heart, Lung, and Blood Institute; National High Blood Pressure Education Program Coordinating Committee. The seventh report of the Joint National Committee on prevention, detection, evalu- ation, and treatment of high blood pressure. Hypertension 2003; 42:1206-52.

20. Expert Panel on Detection, Evaluation, and Treatment of High Blood Cholesterol in Adults: Executive Summary of the Third Report of the National Cholesterol Education Program (NCEP) Expert Panel on Detection, Evaluation, and Treatment of High Blood Cholesterol in Adults (Adult Treatment Panel III). JAMA 2001; 285:2486-96.

21. Khalsa A, Karim R, Mack WJ et al. Correlates of prevalent hypertension in a large cohort of HIV-infected women: Womens Interagency HIV Study. AIDS 2007; 21:2539-41.

22. Atlas Corações do Brasil, v 1. Sociedade Brasileira de Cardiologia, Abril 1, 2009. Available at: http://prevencao.cardiol.br/campanhas/coracoesdobrasil/atlas/default.asp/

23. Passos VMA, Assis TD, Barreto SM. Hypertension in Brazil: Estimates from population-based prevalence studies. Epidemiologia e Serviços de Saúde 2006; 15:35-45.

24. Kotler DP. HIV and antiretroviral therapy: lipid abnormalities and associated cardiovascular risk in HIV-infected patients. J Acquir Immune Defic Syndr 2008; 49(Suppl2):7985.

25. Brazilian Ministry of Health, National Program of STD/ AIDS 2008. Consensus for the treatment of adults and adolescents with HIV infection, Brasília, 120pp.

26. Duran AC, Almeida LB, Segurado AA et al. Diet quality of persons living with HIV/AIDS on highly active antiretroviral therapy. J Hum Nutr Diet 2008, 21:346-50

27. Calza L, Manfredi R, Chiodo F. Dyslipidemia associated with antiretroviral therapy in HIV-infected patients. J Antimicrob Chemother 2004, 53:10-4. 